\title{
Intravascular papillary endothelial hyperplasia with pseudoepitheliomatous hyperpasia
}

\author{
Irulandy Ponniah* \\ Department of Oral \& Maxillofacial Pathology, Tamil Nadu Government Dental College \& Hospital, Chennai 600 003, India
}

A 42-year old apparently healthy male presented with the complaints of a swelling and bleeding. History revealed no significant findings except that he was a smoker for 10 -years. On examination, a small mucosal elevation of $1 \times 1 \mathrm{~cm}$ in size with small pin point openings was observed in the right side of the palate close to the midline raphe. Under the clinical impression of necrotizing sialometaplasia, the lesion was excised for histopathological evaluation. The microscopy showed keratinized surface epithelium with pseudoepitheliomatous hyperplasia and dilated endothelial cell lined vascular spaces with adjacent mucous minor salivary glands. High power examination of the vascular spaces revealed projection of the vessel wall into the lumen and covered by endothelial cells with admixed fibrin mesh. The vascular pathology also involved the adjacent minor salivary gland lobules (Figure 1). The differential diagnosis includes hemangioma and necrotizing sialometaplasia. The capillary size dilated blood vessel would indicate hemangioma but the tufted papillary projections are not typical of it. The presence of pseudoepitheliomatous hyperplasia may be confused with the more common necrotizing sialometaplasia, but the latter also show acinar degeneration with preservation of the lobular architecture, squamous metaplasia and inflammation. The present microscopic features are consistent with intravascular papillary endothelial hyperplasia.

\section{Discussion}

The intravascular papillary endothelial hyperplasia (IPEH) or also called as Masson's tumor is a reactive process of the vascular channels in which a tuft or papilla of the vascular wall project into the lumen and covered by endothelial [1,2]. Pathogenetically, currently IPEH has been regard as reactive or reparative vascular proliferation secondary to traumatic vascular stasis [2]. The IPEH was classified into two subtypes; a mixed form (27\%), papillary endothelial hyperplasia changing focally within hemangioma, and a pure form without a vascular lesion (73\%).

IPEH can involve any blood vessel in the body especially in the skin, subcutaneous tissues of the head and neck region, fingers and trunk, but involvement of the blood vessels of the oral cavity is uncommon [2]. According to a recent review only 117 cases have been identified in the oral cavity with predominant number of cases affecting the lower lip, tongue, buccal mucosa, upper lip, while gingiva, floor of the mouth and palate are rarely affected [2]. Clinically, it present as a small, firm superficial masses imparting red or blue discoloration to the overlying skin or mucosa. Histologically, the lesion appear as tuft or papillary stalks of connective tissue attached to the vessel wall

Copyright: (C2018 Massey JC. This is an open-access article distributed under the terms of the Creative Commons Attribution License, which permits unrestricted use, distribution, and reproduction in any medium, provided the original author and source are credited.

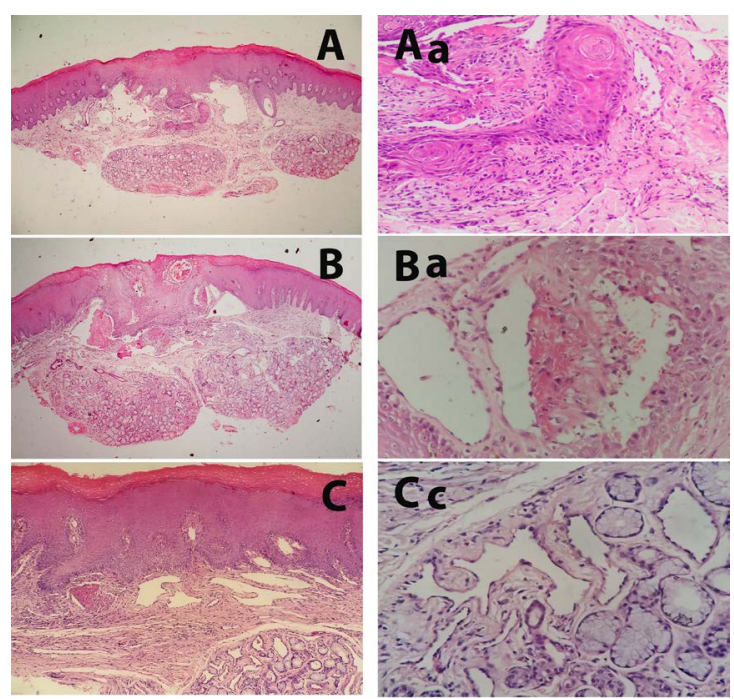

Figure 1. A, shows a scanning magnification photomicrograph of the lesion with pseudoepitheliomatous hyperplasia and dilated, endothelial cell lined vascular channels and underlying apparently normal mucous minor salivary gland lobules. The higher magnification of the pseudoepitheliomatouos hyperplasia and adjacent vascular proliferation is evident in Figure Aa. B, shows a scanning magnification photomicrograph of the deeper sections of lesion with clearly visible vascular proliferation. The higher magnification of the vascular papillary projection is evident in $\mathrm{Ba}$. $\mathrm{C} \& \mathrm{Ca}$, shows lower and higher magnification photomicrograph of more deeper sections with clearly visible papillary process within the mucous salivary gland lobules.[H \& E; x20, x100, x400]

and covered by endothelial cells or a freely floating papilla within the vessel lumen. Depending upon the site and cellularity, the differential includes hemangioma, lymphangioma, arterio-venous malformations, pyogenic granuloma and even angiosarcoma [2].

In conclusion, recognition of the present case in the context of oral soft tissue is important especially to distinguish it from the relatively more frequent necrotizing sialometalasia which frequently presents with pseudoepitheliomatouos hyperplasia of the surface epithelium.

\section{Reference}

1. Clearkin KP, Enzinger FM (1976) Intravascular papillary endothelial hyperplasia. Arch Pathol Lab Med 10: 441-444.

2. Sarode GS, Sarode SC, Karmarkar SP (2014) Oral intravascular papillary endothelial hyperplasia (Masson's tumor): a review of literature. J Oral Maxillofac Surg Med Pathol 26: 73-79.

*Correspondence to: Irulandy Ponniah, Department of Oral \& Maxillofacial Pathology, Tamil Nadu Government Dental College \& Hospital, Chennai 600 003, India, E-mail: salivaryduct@yahoo.co.uk

Received: June 18, 2018; Accepted: June 24, 2018; Published: June 30, 2018 